\title{
Postural Tachycardia Syndrome: Beyond Orthostatic Intolerance
}

\author{
Emily M. Garland ${ }^{1,2,5}$ • Jorge E. Celedonio ${ }^{1,2,6}$ • Satish R. Raj ${ }^{1,2,3,4}$
}

Published online: 22 July 2015

(C) Springer Science+Business Media New York 2015

\begin{abstract}
Postural tachycardia syndrome (POTS) is a form of chronic orthostatic intolerance for which the hallmark physiological trait is an excessive increase in heart rate with assumption of upright posture. The orthostatic tachycardia occurs in the absence of orthostatic hypotension and is associated with a $>6$-month history of symptoms that are relieved by recumbence. The heart rate abnormality and orthostatic symptoms should not be caused by medications that impair autonomic regulation or by debilitating disorders that can cause tachycardia. POTS is a "final common pathway" for a number of overlapping pathophysiologies, including an autonomic neuropathy in the lower body, hypovolemia, elevated
\end{abstract}

This article is part of the Topical Collection on Autonomic Dysfunction

Emily M. Garland

Emily.garland@vanderbilt.edu

Jorge E. Celedonio

Jorge.celedonio@vanderbilt.edu

Satish R. Raj

satish.raj@ucalgary.ca

1 Autonomic Dysfunction Center, Vanderbilt University School of Medicine, Nashville, TN, USA

2 Department of Medicine, Vanderbilt University School of Medicine, Nashville, TN, USA

3 Department of Pharmacology, Vanderbilt University School of Medicine, Nashville, TN, USA

4 Department of Cardiac Sciences, Libin Cardiovascular Institute of Alberta, University of Calgary, GAC70, HRIC Building, 3280 Hospital Drive NW, Calgary, AB T2N 4Z6, Canada

5 Division of Clinical Pharmacology, Department of Medicine, Vanderbilt University, 116121 st Avenue South, Nashville, TN 37232-2195, USA

6 Division of Clinical Pharmacology, Department of Medicine, Vanderbilt University, 536 Robinson Research Building, 2222 Pierce Avenue, Nashville, TN 37232-6602, USA sympathetic tone, mast cell activation, deconditioning, and autoantibodies. Not only may patients be affected by more than one of these pathophysiologies but also the phenotype of POTS has similarities to a number of other disorders, e.g., chronic fatigue syndrome, Ehlers-Danlos syndrome, vasovagal syncope, and inappropriate sinus tachycardia. POTS can be treated with a combination of non-pharmacological approaches, a structured exercise training program, and often some pharmacological support.

Keywords Tachycardia $\cdot$ Orthostatic $\cdot$ Autonomic . Treatment $\cdot$ Non-pharmacological $\cdot$ Medication

\section{Introduction}

Postural tachycardia syndrome (POTS) is a form of chronic orthostatic intolerance in which upright posture is associated with an excessive increase in heart rate (HR) and incapacitating symptoms. An expert consensus statement [1] defines POTS as a HR increment $\geq 30$ beats $/$ min within $10 \mathrm{~min}$ of standing or head-up-tilt (HUT) which is sustained in the absence of orthostatic hypotension (a drop $>20 \mathrm{mmHg}$ in systolic blood pressure (BP) or $>10 \mathrm{mmHg}$ in diastolic BP). Children must meet a higher HR threshold $\geq 40$ beats $/ \mathrm{min}$ for a diagnosis due to their greater physiologic orthostatic tachycardia. Patients with POTS experience cardiac and non-cardiac presyncopal symptoms chronically ( $\geq 6$ months). POTS is not considered to be a unique disease but rather the common phenotype of a number of heterogeneous, overlapping pathophysiological processes [2].

POTS is estimated to affect approximately 500,000 [3] to 3 , 000,000 individuals in the USA, with a female to male ratio of $4-5: 1$. There is no confirmed explanation for this female predominance in POTS, although lower orthostatic tolerance in 
healthy females compared with males has been linked to a smaller upright stroke volume [4]. Patients are often young women of childbearing age whose work productivity and quality of life are negatively affected [5]. Functional impairment in patients with POTS has been reported to be similar to that in chronic obstructive pulmonary disease and congestive heart failure [6]; $25 \%$ are unable to work as a result of their disability [7]. The natural history of POTS is not clear, but it does not appear to increase the risk of mortality $[8 \bullet \cdot]$.

\section{Hemodynamic Physiology of Standing}

With assumption of upright posture, blood shifts from the chest to the lower abdomen, buttocks, and legs and from the vasculature into the interstitial space. The decrease in circulating blood volume stimulates compensatory physiological adjustments that are impaired with hypovolemia and POTS. Normally, standing reduces venous return, causing a transient decline in both cardiac filling and arterial pressure and a decrease in stroke volume. As baroreceptors are unloaded, compensatory sympathetic activation increases HR and vascular tone. With time, venous return and cardiac output are restored. Hence, a normal response to standing is a $10-30$ beat $/ \mathrm{min}$ increase in HR, a negligible change in systolic BP, and a $\sim 5 \mathrm{mmHg}$ increase in diastolic BP [2]. In a condition of resting hypovolemia, the body cannot adequately compensate for the orthostatic decrease in blood volume [9], and upright HR is elevated [4]. Patients with POTS may experience an exaggerated orthostatic shift in plasma volume [10]. Venous return remains decreased, so standing cardiac output and stroke volume are not normalized, and HR is elevated in comparison to healthy control subjects [11-13].

\section{Clinical Presentation of POTS}

\section{Diagnostic Criteria}

The earliest description of POTS may have come from DaCosta in 1871 [14], who described a syndrome of inappropriate tachycardia and palpitations in Civil War soldiers. This ailment was termed "irritable heart" or "soldier's heart" [11]. Different nomenclature was used through the years until the "idiopathic postural orthostatic tachycardia syndrome" was defined in 1993 by Schondorf and Low as a symptomatic increase in HR of 30 beats/min or more within $10 \mathrm{~min}$ of HUT or standing, or a HR while upright exceeding 120 beats/min, without orthostatic hypotension [15]. In our experience, it is uncommon to diagnose POTS based on the 120 beats/min criterion. POTS was recognized in adolescents by Stewart et al. in 1999 [16]. HUT tests and stand tests are standardized methods to assess an individual's response to a change in posture. The patient can be placed securely on a tilt table with continuous or intermittent BP and HR monitoring. Following baseline measurements, the table is inclined to a $70-80^{\circ}$ head-up angle for $10 \mathrm{~min}$. A marked rise in HR in POTS is reversed when the tilt table is returned to a flat position. A similar threshold for HR increase is generally used to diagnose POTS with HUT and a standing test, despite the different physiological responses. Active standing engages the "skeletal muscle pump" while the HUT does not. Accordingly, the orthostatic tachycardia is greater with the HUT test in both patients with POTS and control subjects with prolonged tests, but the orthostatic tachycardia is comparable between HUT and active stand for the 10 min used for the POTS criterion [17•].

The orthostatic tachycardia of POTS is exaggerated in the morning compared to the evening. To optimize diagnostic sensitivity, it is recommended that postural testing be performed in the morning [18].

The mere observation of orthostatic tachycardia is not sufficient for a diagnosis of POTS [2] (Table 1). The HR abnormality must be accompanied by chronic ( $>6$ months) orthostatic symptoms that occur in the absence of prolonged bed rest or deconditioning, use of medications that impair autonomic regulation (vasodilators, diuretics, antidepressants, or anxiolytic agents), or other chronic debilitating disorders that might cause tachycardia (such as dehydration, anemia, or hyperthyroidism) [19]. Despite earlier controversy over its existence, the report by Schondorf [15] and the more recent consensus statement [1] have increased awareness of POTS as a syndrome.

\section{Common Clinical Features}

\section{Orthostatic Symptoms}

Both cardiac symptoms, such as rapid palpitations, lightheadedness, chest discomfort, and dyspnea, and noncardiac symptoms, such as mental clouding, headache, nausea, tremulousness, generalized weakness, and blurred or tunnel vision, are evident in POTS patients during upright posture [19]. An electrocardiogram (ECG), 24-h Holter monitor, and echocardiogram might be needed to rule out a cardiac etiology

Table 1 Diagnostic criteria for postural tachycardia syndrome

- Increase in heart rate $\geq 30 \mathrm{bpm}$ within $10 \mathrm{~min}$ of upright posture (tilt test or stand) from a supine position

- Heart rate increase must be $>40 \mathrm{bpm}$ in patients $<20$ years

- Associated with a constellation of symptoms that are worse with upright posture and that improve with recumbence

- Chronic symptoms that have lasted for $>6$ months

- In the absence of other disorders or medications that are known to predispose to orthostatic tachycardia 
for the tachycardia in suspected cases of POTS. The tachycardia of POTS is a sinus tachycardia. An ECG should be done to rule out the presence of an accessory bypass tract or any abnormalities of cardiac conduction [11]. Chest pain in POTS is rarely from coronary artery obstruction, but it may be associated with ECG changes when patients are upright [20]. A Holter monitor can supply information on mean HR and its variability during various prescribed or routine activities that precipitate orthostatic symptoms. It might be used to exclude a re-entrant dysrhythmia, especially when the patient reports paroxysmal tachycardia with a sudden onset and offset [19]. It cannot be used to diagnose POTS, since it does not provide information on body position. An echocardiogram may be needed to exclude structural cardiac abnormalities before making a diagnosis of POTS.

Many patients with POTS are diagnosed with migraine headaches. Orthostatic headaches may be related to decreases in spinal venous pressure and volume of cerebrospinal fluid due to an absolute or orthostatic hypovolemia [21].

A dark red-blue discoloration of the legs might occur with standing, extending from the feet to above the knees in $\sim 50 \%$ of patients with POTS. This acrocyanosis in POTS is not due to increased venous compliance [22,23] but may be caused by a decrease in blood flow to the skin, possibly related to abnormal cutaneous nitric oxide activity [24].

\section{Non-orthostatic Symptoms}

In addition to orthostatic symptoms in POTS, patients experience non-specific signs and symptoms that seem unrelated to postural intolerance or excessive tachycardia [25]. These might or might not be associated with the autonomic nervous system and can also occur in individuals without POTS. Autonomic problems in POTS might include gastrointestinal complaints, such as abdominal pain, nausea and irritable bowel syndrome, as well as bladder symptoms and abnormal sudomotor regulation $[19,26]$. More generalized complaints in patients with POTS include hypermobile joints, exercise intolerance, migraine headaches, sleep disturbances, and fatigue [19].

\section{Symptom Triggers}

Patients frequently report symptom onset following acute stressors (e.g., pregnancy, a traumatic event, surgery, or a viral illness) $[2,26]$. Symptoms can be exacerbated by simple activities of daily life like standing still, exercise, food or alcohol ingestion, or heat exposure [26].

\section{Psychological Profile in POTS}

Patients with POTS commonly present with symptoms of depression and anxiety. Yet a structured evaluation using criteria from the Diagnostic and Statistical Manual (fourth edition, text revision) did not identify a higher incidence of major depressive disorder, anxiety disorders, or substance abuse in POTS patients than the general population [27]. Furthermore, the HR increase in patients is not a response to anxiety [28]. The palpitations, hyperventilation, and tremulousness of POTS can be misinterpreted as symptoms of anxiety. Although many patients with POTS complain of "memory problems" and "mental clouding," these might actually represent decreased attention and concentration [27]. A comprehensive neuropsychological evaluation of 28 patients in a seated position found deficits in selective attention and cognitive processing, as well as impaired executive functioning. Memory function did not differ from healthy controls [29••].

\section{Disorders Overlapping with POTS}

Cardiovascular autonomic function tests [30] to evaluate sympathetic vasoconstriction and cardiac parasympathetic responses should be performed in presumed POTS patients to rule out more severe forms of autonomic failure. Intact vagal function can be demonstrated by a normal sinus arrhythmia ratio in response to deep breathing. A Valsalva maneuver is useful to assess both vagal and sympathetic components of the baroreflex [25]. Patients with POTS often have a vigorous pressor response, with exaggerated BP recovery and overshoot both before and after release [19]. Conversely, patients with impaired vasoconstriction (e.g., patients with partial autonomic neuropathy) can have an impaired Valsalva pressure recovery.

\section{Chronic Fatigue Syndrome}

POTS patients describe poorer sleep quality, more daytime sleepiness, greater fatigue, and substandard quality of life compared to healthy subjects [5]. These reports are consistent with a reduction in sleep efficiency determined by actigraphy [31•]. A higher measure for sleep problems is strongly negatively correlated with the RAND-36 physical health composite score and significantly, but to a lesser degree, correlated with the mental health composite score [5]. These data suggest that the impaired health-related quality of life measured in POTS can be attributed significantly to sleep problems [5].

Chronic fatigue syndrome (CFS) is characterized by persistent or relapsing unexplained fatigue and related symptoms of at least 6 months duration. Like POTS, CFS is a clinical syndrome that is more commonly diagnosed in females. For a CFS diagnosis, a patient must meet criteria for physical, mental and post-exertional fatigue, sleep disturbances, pain, neurological or cognitive manifestations (such as confusion, concentration, and memory problems), and symptoms of autonomic, neuroendocrine, or immune disturbances [32]. Patients 
with POTS have a high prevalence of chronic fatigue (48$77 \%)$ and of CFS (17-23\%) [8••, 33]. When patients were grouped according to whether or not they met the criteria for CFS [33], fatigue symptoms, orthostatic changes in HR and BP after $10 \mathrm{~min}$, supine and upright plasma norepinephrine, and plasma volume were similar for the two groups. Plasma renin activity and aldosterone tended to be higher in patients with CFS. Autonomic testing indicated a similar autonomic profile but higher sympathetic tone in patients with CFS. Okamoto et al. proposed that CFS is part of the POTS spectrum [33].

\section{Ehlers-Danlos Syndrome}

Ehlers-Danlos syndrome (EDS) includes heterogeneous disorders associated with inherited abnormalities of collagen. Patients are characterized by skin hyperextensibility, joint hypermobility, and fragile connective tissue [34•]. Patients with EDS type III (EDS-Hypermobility) frequently have symptoms of autonomic dysregulation that are also common in patients with POTS: palpitations, lightheadedness, chest pain, presyncope, and syncope [35]. In addition, autonomic test results in these patients are consistent with disturbed sympathetic cardiovascular control, similar to POTS. More recent studies of autonomic symptoms/function and quality of life in patients with the hypermobility type of EDS confirm a high prevalence of POTS-like orthostatic symptoms and orthostatic intolerance in these patients. Similar to POTS patients, symptoms can be triggered by exercise, meals, and a hot environment, in addition to standing [36•,37].

Wallman et al. ascertained the prevalence of EDS in their POTS population: $18 \%$ of POTS patients met criteria for EDS, compared to a $0.02 \%$ prevalence in the general population and $4 \%$ prevalence in their autonomic clinic patients without POTS [34•]. Based on experience at his autonomic clinic, Professor Mathias reported that EDS type III is the most common disorder associated with POTS [38].

The exact nature of the relationship between POTS and EDS-Hypermobility is unknown. Connective tissue abnormalities in EDS could lead to vascular laxity and predispose patients to orthostatic blood pooling in the lower extremities and orthostatic intolerance $[8 \bullet \bullet, 35]$. Alternatively, these patients might have a peripheral neuropathy that could contribute to autonomic impairment $[36 \bullet, 37]$.

\section{Vasovagal Syncope}

Vasovagal syncope (VVS) and POTS overlap clinically, and both diagnoses may be appropriate for a given patient [8••]. A HUT test can be helpful in the differential diagnosis. Patients with vasovagal syncope are able to maintain their BP for several minutes following HUT and then experience a rapid drop in BP as stroke volume and cardiac output decrease. Ensuing cerebral hypoperfusion causes a sudden loss of consciousness [39, 40]. Patients with POTS, on the other hand, have a fairly steady BP when tilted up, but orthostatic tachycardia is enhanced as sympathetic tone increases to compensate for the decrease in circulating blood volume [2]. As the HR rises within the initial 10 min, patients complain of presyncopal symptoms, but they rarely faint. Only $30 \%$ or so of POTS patients actually experience syncope [2].

\section{Inappropriate Sinus Tachycardia}

Inappropriate sinus tachycardia (IST) is another disorder having overlapping clinical features with POTS. IST also predominantly affects young women and is characterized by presyncopal symptoms and abnormally high HRs [10]. IST differs from POTS in that the tachycardia can be independent of body position, and resting HR commonly exceeds 100 beats/min, consistent with higher sympathetic tone and decreased parasympathetic tone in IST relative to patients with POTS and healthy controls [41•]. In POTS, the orthostatic change in HR surpasses that in IST. The intrinsic HR does not differ between POTS and IST patients [41•].

\section{Pathophysiology of POTS}

POTS is a "final common pathway" for a number of overlapping pathophysiologies [2]. Although patterns of clinical features have been used to subtype patients, these classifications are mainly descriptive and are not mutually exclusive (see Fig. 1).

\section{Neuropathic POTS}

Neuropathic POTS was first described when activation of the sympathetic nervous system increased norepinephrine spillover in the lower limbs of some patients to a lesser extent than in healthy controls, despite similar responses in the arms [42]. Sympathetic denervation obstructs compensatory vascular constriction during upright posture, allowing blood to pool in the splanchnic vasculature and lower extremities $[7,8 \cdot \bullet$, 43]. The resulting decrease in venous return leads to the sympathetic activation and tachycardia of POTS. Norepinephrine spillover is not a practical clinical test. A thermoregulatory sweat test or a Quantitative Sudomotor Axon Reflex Test (QSART), quantitative sensory testing, or a skin biopsy can also be used to determine whether an autonomic neuropathy exists $[25,44 \bullet \bullet]$. 
Fig. 1 Many patients think about the different subgroups of POTS as distinct and mutually exclusive groups (Panel a). While the subgroups are useful pathophysiological concepts, in clinical practice, the subtype labels are often used to describe individual test findings, and the same patient can fit into more than one overlapping subtype Panel b) a

Mutually Distinct Subtypes (Assumed)

b

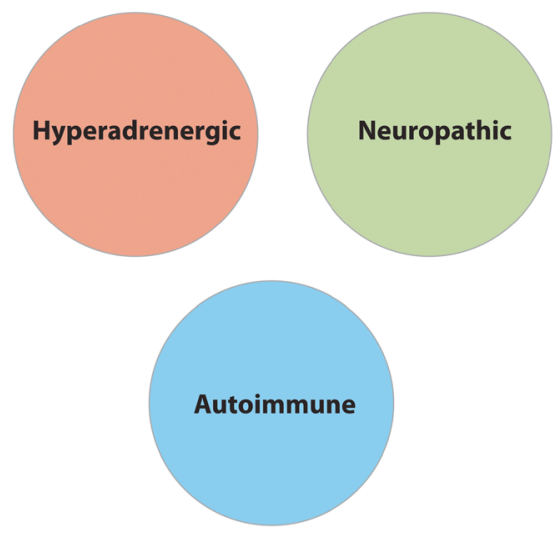

Overlapping Subtypes in POTS (Reality)

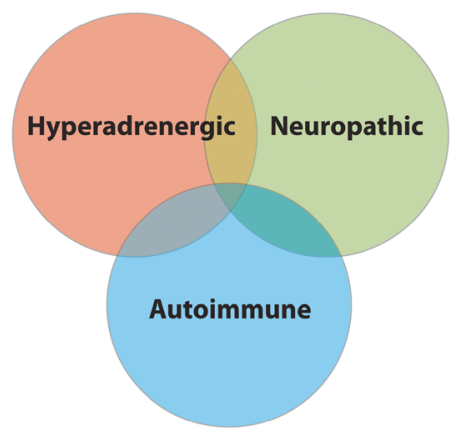

\section{Hypovolemia and the Renin-Angiotensin-Aldosterone System in POTS}

One of the more consistent findings in patients with POTS is a deficit in total blood, plasma, and red cell volume [13, 45, 46]. Lin has proposed that a decrease in oxygenation related to the low red blood cell volume could exacerbate symptoms of orthostatic intolerance [47]. Another cohort of patients with POTS might not have a hypovolemia but an exaggerated decrease in volume on standing [10].

The renin-angiotensin-aldosterone system is fundamental for the regulation of blood volume [48]. It is activated by upright posture [49] and by a reduction in blood volume [46]. Plasma renin activity, angiotensin II, and aldosterone would be expected to be elevated in POTS in response to the hypovolemia. Some POTS patients with hypovolemia, however, have inappropriately low standing plasma renin activity and aldosterone compared with normovolemic controls $[12,46]$. Circulating angiotensin II levels have been reported to be elevated but without a parallel increase in its metabolite angiotensin (1-7) $[50,51]$. These paradoxical findings suggest that POTS patients might have decreased angiotensin II metabolism and that dysregulation by the renin-angiotensin-aldosterone system might contribute to hypovolemia in POTS $[50,51]$.

\section{Central Hyperadrenergic POTS}

Although the elevated sympathetic tone in POTS is often secondary to another pathophysiological mechanism, such as neuropathy or hypovolemia, it can also be the primary underlying problem [19]. Furlan et al. reported increased sympathetic tone in patients with POTS [52]. Resting sympathetic nerve activity, measured by microneurography, is elevated. A spectral analysis index of sympathetic function and plasma norepinephrine are sometimes higher at supine rest and increase more with HUT in POTS $[52,53]$. Plasma norepinephrine levels should be determined in patients with POTS while in steady state in the supine and upright positions (at least 10 min in each position). When measured during upright posture, norepinephrine is elevated in many patients with POTS $(>3.55 \mathrm{nmol} / \mathrm{L}(600 \mathrm{pg} / \mathrm{mL})$ and sometimes $>5.91 \mathrm{nmol} / \mathrm{L}(1000 \mathrm{pg} / \mathrm{mL}))$, consistent with the sympathetic neuronal activation elicited by standing in these patients [19]. This is sometimes used as a criterion for the "hyperadrenergic subtype" of POTS.

An exaggerated sympathetic vasoconstrictor response during the recovery and overshoot phases of the Valsalva maneuver may also reflect a hyperadrenergic state in patients with POTS $[2,19]$. These patients may have orthostatic hypertension (increase in systolic blood pressure $>10 \mathrm{mmHg}$ on standing) and complain of tremor, anxiety, and cold, sweaty extremities [7, 25].

\section{Norepinephrine Transporter Deficiency}

A very rare form of hyperadrenergic POTS is caused by a lossof-function mutation in the gene for the norepinephrine transporter (NET) [54]. NET is a clearance transporter for norepinephrine, and this genetic form of NET deficiency leads to increased synaptic norepinephrine. The mutation has been identified in one kindred thus far. Lambert et al. have reported that some POTS patients may have decreased expression of NET protein, leading to a functional NET deficiency [55].

\section{Mast Cell Activation}

Some POTS patients present with severe flushing in addition to their tachycardia and have an associated mast cell activation disorder. These patients often have a hyperadrenergic phenotype, with both orthostatic tachycardia and hypertension in the upright position, as well as dyspnea, headache, lightheadedness, chest discomfort, and gastrointestinal symptoms. It is unknown whether sympathetic stimulation in these patients induces mast cell degranulation or whether primary mast cell activation causes release of vasodilators and compensatory sympathetic activation 
[56]. This diagnosis is most often made with an elevated histamine metabolite $(>230 \mu \mathrm{g}$ methylhistamine/g creatinine) in a 4-h urine sample started at the onset of a severe flushing spell. In this manner, we get a urine sample that is enriched for methylhistamine. In our experience, a 24-h urine sample is usually negative in these patients, since methylhistamine release is episodic and not constant. Plasma tryptase levels and urinary prostaglandin D2 may also be elevated.

\section{Physical Deconditioning}

Fatigue and exercise intolerance with reduced stroke volume and reflex tachycardia are typical manifestations of cardiovascular deconditioning as well as POTS $[13,25]$. Due to their disability, many patients with POTS have restrictions on their activity and can become deconditioned over time. Alternatively, an individual can become physically deconditioned secondary to another illness or bed rest and develop a clinical phenotype that resembles POTS. Although it may not be clear if deconditioning is a primary problem or secondary to POTS, many patients with POTS do have cardiovascular deconditioning and do benefit from a program of aerobic exercise and resistance training [13].

\section{Autoimmune/Autoantibodies}

A significant minority of POTS patients are diagnosed following a virus-like syndrome. This suggests an autoimmune cause for POTS in some patients. It is noteworthy that the prototypical POTS patient (woman of childbearing age) is of the same demographic as a typical patient with an autoimmune disorder. A low titer of an antibody to the ganglionic acetylcholine receptor (nAChR) was reported in $15 \%$ of adult POTS patients evaluated at the Mayo Clinic between 1993 and 2003 [26]. However, this has not been consistent with our clinical practice, where this antibody is rarely seen in POTS patients.

Recently, Li et al. [57••] presented evidence from two cohorts of POTS patients for $\alpha 1$ adrenergic receptor (AR) autoantibodies acting as partial peripheral receptor antagonists. Compensatory sympathetic activation to maintain adequate vasoconstriction could then induce tachycardia via $\beta$-ARs. $\beta 1$-AR- and $\beta 2$-AR-activating autoantibodies could also contribute to the tachycardia. These data suggest an exciting new pathophysiology for some patients with POTS. However, only a small number of patients were studied, and further research is needed to establish clinical significance.

\section{Treatment of POTS}

A detailed history and physical exam are a requisite initial step in the evaluation of a patient with POTS. The history should determine whether the POTS can be traced back to a particular illness or trauma, the frequency of symptoms, symptom triggers, the severity of the orthostatic intolerance, associated illnesses, and the impact of POTS on daily functions and quality of life. Family history should also be queried. The answers to these questions help direct the management and treatment of the patient (Table 2).

\section{Non-pharmacological Treatment of POTS}

Patients are encouraged to increase their blood volume by drinking 2-3 L/day of water and ingesting $>200 \mathrm{mEq}$ sodium/day (Heart Rhythm Society (HRS) 2015 Statement Class IIb recommendation) [8••]. Intravenous saline (1-2 L) can quickly expand blood volume and lessen tachycardia in POTS patients [58]. IV saline for an acute clinical decompensation in POTS is a HRS Class IIa recommendation, but chronic regular saline infusions are not recommended (HRS Class III) due to concerns about complications related to longterm venous access $[8 \cdot \bullet]$.

Non-pharmacologic approaches to counteract the inadequate physiological response to upright posture can be beneficial in POTS. Abdominal compression with elastic waisthigh support hose and abdominal binders can help decrease splanchnic-mesenteric venous pooling during standing [43]. The increase in venous return and stroke volume can decrease the orthostatic tachycardia $[19,59]$.

\section{Exercise in POTS}

Excessive tachycardia in POTS occurs during exercise as well as during standing $[60,61]$, and patients experience significant exercise intolerance $[9,19]$. As patients find it difficult to exercise, they can become increasingly deconditioned. The three-month Dallas Program, which involves aerobic exercise coupled with resistance training, improves orthostatic and exercise tachycardia, symptoms, and quality of life [13, 62, 63]. Improvement is related to an increase in the size of the heart and increased blood volume [13]. The improved stroke volume decreases tachycardia.

The challenge with an exercise program in POTS is the marked exercise intolerance and debilitating post-exercise fatigue. The Dallas Program focuses on starting with seated or supine exercises (e.g., rowing machine, recumbent cycle, or swimming) three times per week. Patients must be informed that it can take 5-6 weeks before they notice any improvement, and in the interim, the patients may transiently feel worse. A structured and progressive exercise program is a HRS Class IIa recommendation $[8 \bullet \bullet$.

\section{Pharmacological Treatment of POTS}

The US Food and Drug Administration has not approved any drugs for the treatment of POTS. Although the successful off- 
Table 2 Treatments for postural tachycardia syndrome

\begin{tabular}{|c|c|c|c|}
\hline Treatment & Dose & HRS class & Comments \\
\hline \multicolumn{4}{|c|}{ Non-pharmacological treatments } \\
\hline Oral water & $2-3 \mathrm{~L} /$ day & $\mathrm{Ilb}$ & \\
\hline High-sodium diet & $>200 \mathrm{mEq} /$ day & $\mathrm{Ilb}$ & Best if done with diet, but $\mathrm{NaCl}$ supplements can be used \\
\hline IV saline-ACUTE & $1-2 \mathrm{~L}$ & Ila & Can be used at times of clinical decompensation to avoid hospital admission \\
\hline IV saline-CHRONIC & 1-2 L daily-weekly & III & Not recommended due to risks of vascular access complications \\
\hline $\begin{array}{l}\text { Waist-high compression } \\
\text { stockings }\end{array}$ & $30-40 \mathrm{mmHg}$ & & $\begin{array}{l}\text { Lower abdomen is major site of blood pooling when upright. If used, } \\
\text { stockings should be pantyhose style }\end{array}$ \\
\hline $\begin{array}{l}\text { Abdominal binders or } \\
\text { corset-like garments }\end{array}$ & & & $\begin{array}{l}\text { If leg compression is not tolerated, abdomen/pelvis only } \\
\text { alternatives might be an option }\end{array}$ \\
\hline Exercise training program & Every other day $\times 30+$ minutes & IIa & $\begin{array}{l}\text { Focus on aerobic reconditioning starting with seated/supine exercises; } \\
\text { benefits can take 4-6 weeks to manifest }\end{array}$ \\
\hline $\begin{array}{l}\text { Impedance threshold } \\
\text { breathing device }\end{array}$ & $7 \mathrm{~cm} \mathrm{H}_{2} \mathrm{O}$ & & $\begin{array}{l}\text { Breathing through this when feeling unwell can acutely increase stroke } \\
\text { volume and decrease heart rate }\end{array}$ \\
\hline \multicolumn{4}{|l|}{ Pharmacological treatments } \\
\hline Propranolol & 10-20 mg PO QID & $\mathrm{IIb}$ & Useful to decrease the heart rate in POTS and improve symptoms acutely \\
\hline Alpha methyldopa & $125-250 \mathrm{mg}$ PO BID & $\mathrm{IIb}$ & $\begin{array}{l}\text { Sometimes needed with prominent hyperadrenergic features; can cause } \\
\text { profound fatigue, drowsiness or mental clouding if too much is given }\end{array}$ \\
\hline Pyridostigmine & $30-60 \mathrm{mg}$ PO TID & $\mathrm{IIb}$ & $\begin{array}{l}\text { May restrain heart rate by increasing parasympathetic tone; diarrhea can be } \\
\text { a limiting side effect }\end{array}$ \\
\hline Midodrine & $2.5-10 \mathrm{mg}$ PO Q4h $\times 3$ & $\mathrm{IIb}$ & $\begin{array}{l}\text { Vasocontrictor and venoconstrictor; may improve venous return and } \\
\text { decrease reflex tachycardia }\end{array}$ \\
\hline Octreotide & $12.5-50 \mathrm{mcg}$ SQ BID & & $\begin{array}{l}\text { Injectable splanchnic vasoconstrictor; may use a long-acting preparation once } \\
\text { dose has been stabilized }\end{array}$ \\
\hline Ivabradine & $5-7.5 \mathrm{mg}$ BID & & $\begin{array}{l}\text { Funny channel blocker that has shown benefit in IST patients, and in case } \\
\text { reports in POTS patients }\end{array}$ \\
\hline Fludrocortisone & $0.05-0.2 \mathrm{mg}$ PO daily & $\mathrm{IIb}$ & Mineralocorticoid that enhances renal sodium reabsorption in the short term \\
\hline DDAVP (desmopressin) & $0.2 \mathrm{mg}$ PO per dose & & $\begin{array}{l}\text { Encourages renal free water retention and acute blood volume expansion; } \\
\text { hyponatremia can result if given in excess }\end{array}$ \\
\hline Sertraline & $50 \mathrm{mg}$ daily & & $\begin{array}{l}\text { Sertraline does not have any significant negative hemodynamic effects in } \\
\text { POTS; it may be helpful in coping with chronic illness }\end{array}$ \\
\hline SNRI/NETi medications & & III & $\begin{array}{l}\text { Drugs that block the norepinephrine transporter can worsen tachycardia } \\
\text { and symptoms in POTS patients }\end{array}$ \\
\hline Modafinil & 50-200 mg PO BID & & $\begin{array}{l}\text { This has anecdotally been reported to help with the fatigue and "brain fog" } \\
\text { in POTS; it has only minimal heart rate increase in most patients }\end{array}$ \\
\hline
\end{tabular}

HRS Class refers to the class of Recommendation from the Heart Rhythm Society Statement on postural tachycardia syndrome. Class IIa and IIb is a favorable recommendation, but in the absence of high-level evidence. Class III is a negative recommendation cautioning against the use of a treatment $I V$ intravenous, $P O$ oral administration, $S Q$ subcutaneous administration, BID twice daily, TID 3 times daily, $Q I D 4$ times daily, SNRI serotoninnorepinephrine reuptake inhibitor, NETi norepinephrine transporter inhibitor

label use of different medications might be expected to be influenced by the POTS subtype, Thieben et al. did not find this to be true with a variety of medications [26].

After the initiation of non-pharmacological treatments, our approach is to decrease the influence of sympathetic tone on the heart. The non-selective $\beta$-AR antagonist propranolol acutely restrains orthostatic tachycardia and symptoms at doses that appear to be low enough (10-20 mg) to avoid the side effect of significant fatigue [64]. The decrease in standing HR was verified in a four-week trial of long-acting propranolol although quality of life was not improved [62]. Propranolol is a HRS Class IIb recommendation [8••]. Central sympatholytics (e.g., clonidine and methyldopa) can also be used to decrease sympathetic tone in patients with prominent hyperadrenergic features, but might produce drowsiness and worsening of the mental clouding [19] (HRS Class IIb) [8••].

Increasing parasympathetic tone with pyridostigmine can also curtail HR in POTS [65] (HRS Class IIb) [8・•]. This agent inhibits acetylcholinesterase, thereby increasing the availability of acetylcholine at both the autonomic ganglia and the peripheral muscarinic receptors. Pyridostigmine ameliorates symptoms in patients with POTS, although nausea, vomiting, and diarrhea from gut activity may lead to discontinuation in $20 \%$ of patients [66].

Midodrine, a pro-drug of an $\alpha 1$-AR agonist, can increase peripheral resistance in POTS by stimulating vasoconstriction. 
Improvement in symptoms and orthostatic tachycardia can be associated with scalp tingling and goosebumps [58], and midodrine can cause urinary retention [67]. Midodrine is a HRS Class IIb recommendation in POTS [8••].

The somatostatin analog octreotide is a vasoconstrictor that mainly affects the splanchnic circulation. This effect during standing helps to maintain venous return in POTS and inhibits the compensatory increase in HR following acute and chronic administration $[68,69]$. However, octreotide is only available in an injectable form, and this likely limits its use and patient acceptability.

Ivabradine is a cardioselective agent that slows HR via inhibition of the funny channel current $\left(\mathrm{I}_{\mathrm{f}}\right)$ in the cardiac sinoatrial node but does not affect BP. Ivabradine is approved for the treatment of heart failure (USA and Europe) and angina (Europe). A retrospective case series found decreased tachycardia and symptoms in POTS patients [70].

Another approach that can be combined with vasoactive medication is administration of medications to expand blood volume. Fludrocortisone is a synthetic corticosteroid that preferentially binds to the mineralocorticoid receptor and acutely increases sodium reabsorption in the distal tubules of the kidney. Fludrocortisone also stimulates potassium excretion, making it necessary to watch for hypokalemia, and it can also worsen migraine headaches $[19,71]$. Fludrocortisone is a HRS Class IIb recommendation [8・•].

Two other agents used to increase blood volume are the vasopressin analog, desmopressin (DDAVP), and erythropoietin. Although DDAVP reduces tachycardia and symptoms $[71,72]$, it can lead to hyponatremia. We have been cautious about the regular use of DDAVP, but we have successfully used this as an "occasional use" medication. With this approach, we have not seen hyponatremia.

Erythropoietin increases red cell mass and may also stimulate vasoconstriction [7]. Potential adverse effects include vascular complications (myocardial infarction and stroke). This, combined with its high cost and the need for injection, makes it a less attractive option [11].

Norepinephrine transporter (NET) inhibitors, or serotoninnorepinephrine reuptake inhibitors (SNRIs), can exacerbate tachycardia in POTS [73••]. The HRS cautions against their use in POTS (HRS Class III) [8••]. Selective serotonin reuptake inhibitors (SSRIs), on the other hand, do not aggravate orthostatic tachycardia or symptoms in POTS patients [74*0]. Whether they have any clinical benefit in POTS has yet to be studied.

\section{The Vanderbilt Approach to the Treatment of POTS}

We will typically start with non-pharmacological approaches. These routinely include increased dietary salt and water intake and the use of compression stockings if tolerated. We routinely encourage our patients to engage in a structured exercise program.

Many of our patients will also require adjunct medications. We find that low-dose propranolol is effective and well tolerated in most patients. As needed, we will then add midodrine and/or fludrocortisone. Other medications are used less commonly and based on individual patient characteristics.

\section{Conclusions}

POTS is a disabling disorder, related to multiple, overlapping pathophysiological mechanisms. The hallmark physiological trait is an excessive increase in HR upon assumption of the upright posture, in the absence of orthostatic hypotension. POTS is not a single disease. A number of non-specific symptoms that are both associated with and independent of upright posture create a clinical phenotype that overlaps with other disorders like CFS. POTS can be treated with a combination of nonpharmacological approaches, a structured exercise training program, and often some pharmacological support.

Acknowledgment Supported in part by NIH grants R01 HL102387, R01 HL071784, P01 HL56693, U54 NS065736, 1 UL1 TR000445 (Clinical and Translational Science Award), and the Paden Dysautonomia Center.

\section{Compliance with Ethics Guidelines}

Conflict of Interest Emily M. Garland and Jorge E. Celedonio report grants from National Institutes of Health, during the conduct of the study.Satish R. Raj reports grants from National Institutes of Health, during the conduct of the study; grants from Medtronic; personal fees from Lundbeck Pharmaceuticals; personal fees from GE Healthcare; and personal fees from Medicolegal Consulting, outside the submitted work.

Human and Animal Rights and Informed Consent This article does not contain any studies with human or animal subjects performed by any of the authors.

\section{References}

Papers of particular interest, published recently, have been highlighted as:

- Of importance

•. Of major importance

1. Freeman R, Wieling W, Axelrod FB, Benditt DG, Benarroch E, Biaggioni I, et al. Consensus statement on the definition of orthostatic hypotension, neurally mediated syncope and the postural tachycardia syndrome. Clin Auton Res. 2011;21:69-72.

2. Raj SR. The postural tachycardia syndrome (POTS): pathophysiology, diagnosis \& management. Indian Pacing Electrophysiol J. 2006;6:84-99. 
3. Robertson D. The epidemic of orthostatic tachycardia and orthostatic intolerance. Am J Med Sci. 1999;317:75-7.

4. Fu Q, Witkowski S, Okazaki K, Levine BD. Effects of gender and hypovolemia on sympathetic neural responses to orthostatic stress. Am J Physiol Regul Integr Comp Physiol. 2005;289:R109-16.

5. Bagai K, Song Y, Ling JF, Malow B, Black BK, Biaggioni I, et al. Sleep disturbances and diminished quality of life in postural tachycardia syndrome. J Clin Sleep Med. 2011;7:204-10.

6. Benrud-Larson LM, Dewar MS, Sandroni P, Rummans TA, Haythornthwaite JA, Low PA. Quality of life in patients with postural tachycardia syndrome. Mayo Clin Proc. 2002;77:531-7.

7. Grubb BP. Postural tachycardia syndrome. Circulation. 2008;117: 2814-7.

8.• Sheldon RS, Grubb BP, Olshansky B, Shen WK, Calkins H, Brignole M, et al. 2015 heart rhythm society expert consensus statement on the diagnosis and treatment of postural tachycardia syndrome, inappropriate sinus tachycardia, and vasovagal syncope. Heart Rhythm. 2015;12:e41-63. The Heart Rhythm Society has recently published its first consensus statement on the diagnosis and treatment of postural tachycardia syndrome (POTS) and other disorders. While not comprehensive, it provides an excellent starting point for a clinician wanting to learn about the management of POTS.

9. Medow MS, Stewart JM. The postural tachycardia syndrome. Cardiol Rev. 2007;15:67-75.

10. Jacob G, Biaggioni I. Idiopathic orthostatic intolerance and postural tachycardia syndromes. Am J Med Sci. 1999;317:88-101.

11. Johnson JN, Mack KJ, Kuntz NL, Brands CK, Porter CJ, Fischer PR. Postural orthostatic tachycardia syndrome: a clinical review. Pediatr Neurol. 2010;42:77-85.

12. Fu Q, Vangundy TB, Shibata S, Auchus RJ, Williams GH, Levine BD. Menstrual cycle affects renal-adrenal and hemodynamic responses during prolonged standing in the postural orthostatic tachycardia syndrome. Hypertension. 2010;56:82-90.

13. Fu Q, Vangundy TB, Galbreath MM, Shibata S, Jain M, Hastings $\mathrm{JL}$, et al. Cardiac origins of the postural orthostatic tachycardia syndrome. J Am Coll Cardiol. 2010;55:2858-68.

14. DaCosta JM. On irritable heart: a clinical study of a form of functional cardiac disorder and its consequences. Am J Med Sci. 1871;61:17-52.

15. Schondorf R, Low PA. Idiopathic postural orthostatic tachycardia syndrome: an attenuated form of acute pandysautonomia? Neurology. 1993;43:132-7.

16. Stewart JM, Gewitz MH, Weldon A, Munoz J. Patterns of orthostatic intolerance: the orthostatic tachycardia syndrome and adolescent chronic fatigue. J Pediatr. 1999;135:218-25.

17. Plash WB, Diedrich A, Biaggioni I, Garland EM, Paranjape SY, Black BK, et al. Diagnosing postural tachycardia syndrome: comparison of tilt testing compared with standing haemodynamics. Clin Sci (Lond). 2013;124:109-14. This study compared the heart rate (HR) increases with a head up tilt test and a stand test. Over the $10 \mathrm{~min}$ used for the POTS HR criterion, there was not a significant difference, but over $30 \mathrm{~min}$, the HR increases were greater with the tilt test than the stand test.

18. Brewster JA, Garland EM, Biaggioni I, Black BK, Ling JF, Shibao $\mathrm{CA}$, et al. Diurnal variability in orthostatic tachycardia: implications for the postural tachycardia syndrome. Clin Sci (Lond). 2012;122: 25-31.

19. Raj SR. Postural tachycardia syndrome (POTS). Circulation. 2013;127:2336-42.

20. Friesinger GC, Biern RO, Likar I, Mason RE. Exercise electrocardiography and vasoregulatory abnormalities. Am J Cardiol. 1972;30:733-40.

21. Mokri B, Low PA. Orthostatic headaches without CSF leak in postural tachycardia syndrome. Neurology. 2003;61:980-2.
22. Freeman R, Lirofonis V, Farquhar WB, Risk M. Limb venous compliance in patients with idiopathic orthostatic intolerance and postural tachycardia. J Appl Physiol (1985). 2002;93:636-44.

23. Stewart JM. Pooling in chronic orthostatic intolerance: arterial vasoconstrictive but not venous compliance defects. Circulation. 2002;105:2274-81.

24. Stewart JM, Medow MS, Minson CT, Taneja I. Cutaneous neuronal nitric oxide is specifically decreased in postural tachycardia syndrome. Am J Physiol Heart Circ Physiol. 2007;293:H2161-7.

25. Low PA, Sandroni P, Joyner M, Shen WK. Postural tachycardia syndrome (POTS). J Cardiovasc Electrophysiol. 2009;20:352-8.

26. Thieben MJ, Sandroni P, Sletten DM, Benrud-Larson LM, Fealey RD, Vernino S, et al. Postural orthostatic tachycardia syndrome: the Mayo Clinic experience. Mayo Clin Proc. 2007;82:308-13.

27. Raj V, Haman KL, Raj SR, Byrne D, Blakely RD, Biaggioni I, et al. Psychiatric profile and attention deficits in postural tachycardia syndrome. J Neurol Neurosurg Psychiatry. 2009;80:339-44.

28. Masuki S, Eisenach JH, Johnson CP, Dietz NM, Benrud-Larson LM, Schrage WG, et al. Excessive heart rate response to orthostatic stress in postural tachycardia syndrome is not caused by anxiety. J Appl Physiol (1985). 2007;102:896-903.

29.• Arnold AC, Haman K, Garland EM, Raj V, Dupont WD, Biaggioni I, et al. Cognitive dysfunction in postural tachycardia syndrome. Clin Sci (Lond). 2015;128:39-45. This recent study formally looked at neurocognitive testing in POTS patients and healthy control subjects. Selective attention, cognitive processing speed, and measures of executive function are reduced in POTS. Follow-up studies looking at therapeutic approaches are underway.

30. Low PA. Testing the autonomic nervous system. Semin Neurol. 2003;23:407-21.

31. Bagai K, Wakwe CI, Malow B, Black BK, Biaggioni I, Paranjape SY, et al. Estimation of sleep disturbances using wrist actigraphy in patients with postural tachycardia syndrome. Auton Neurosci. 2013;177:260-5. This study used actigraphy watches to objectively assess sleep disturbances in POTS. POTS patients had poor sleep efficiency and more sleep-related symptoms. POTS patients had a mismatch between objective and subjective sleep onset latency, suggesting a sleep-state mismatch.

32. Torpy BDJ, Saranapala M. Chronic Fatigue Syndrome. De Groot LJ, Beck-Peccoz P, Chrousos G, Dungan K, Grossman A, Hershman JM, Koch C, McLachlan R, New M, Rebar R, Singer F, Vinik A, Weickert MO, editors. 2014. South Dartmouth (MA), MDText.com, Inc. Endotext. www.endotext.org

33. Okamoto LE, Raj SR, Peltier A, Gamboa A, Shibao C, Diedrich A, et al. Neurohumoral and haemodynamic profile in postural tachycardia and chronic fatigue syndromes. Clin Sci (Lond). 2012;122: 183-92.

34. Wallman D, Weinberg J, Hohler AD. Ehlers-Danlos syndrome and postural tachycardia syndrome: a relationship study. J Neurol Sci. 2014;340:99-102. This study assessed the incidence of EhlersDanlos syndrome in a cohort of POTS patients and found the incidence of EDS in POTS to be $18 \%$, vs. $4 \%$ in non-POTS patients from an autonomic clinic, and an estimated prevalence of $0.02 \%$ in the general population.

35. Gazit Y, Nahir AM, Grahame R, Jacob G. Dysautonomia in the joint hypermobility syndrome. Am J Med. 2003;115:33-40.

36. De Wandele I, Calders P, Peersman W, Rimbaut S, De Backer T, Malfait F, et al. Autonomic symptom burden in the hypermobility type of Ehlers-Danlos syndrome: a comparative study with two other EDS types, fibromyalgia, and healthy controls. Semin Arthritis Rheum. 2014;44:353-61. The authors took a cohort of EDS patients and assessed their autonomic and other symptoms burden. They found a much higher burden of autonomic symptoms in EDS patients than in control subjects, suggesting that these are extra-articular manifestations of EDS. 
37. De Wandele I, Rombaut L, Leybaert L, Van de Borne P, De Backer $\mathrm{T}$, Malfait F, et al. Dysautonomia and its underlying mechanisms in the hypermobility type of Ehlers-Danlos syndrome. Semin Arthritis Rheum. 2014;44:93-100.

38. Mathias CJ, Low DA, Iodice V, Owens AP, Kirbis M, Grahame R. Postural tachycardia syndrome - current experience and concepts. Nat Rev Neurol. 2012;8:22-34.

39. Fu Q, Verheyden B, Wieling W, Levine BD. Cardiac output and sympathetic vasoconstrictor responses during upright tilt to presyncope in healthy humans. J Physiol. 2012;590:1839-48.

40. Raj SR, Coffin ST. Medical therapy and physical maneuvers in the treatment of the vasovagal syncope and orthostatic hypotension. Prog Cardiovasc Dis. 2013;55:425-33.

41. Nwazue VC, Paranjape SY, Black BK, Biaggioni I, Diedrich A, Dupont WD, et al. Postural tachycardia syndrome and inappropriate sinus tachycardia: role of autonomic modulation and sinus node automaticity. J Am Heart Assoc. 2014;3:e00700. This physiological study used intrinsic heart rate testing to determine the relative autonomic contributions vs. intrinsic heart pacemaker abnormalities in POTS and inappropriate sinus tachycardia (IST). Intrinsic heart rate was not different from controls for either POTS or IST. IST patients had more sympathetic tone and less parasympathetic tone than POTS patients.

42. Jacob G, Costa F, Shannon JR, Robertson RM, Wathen M, Stein M, et al. The neuropathic postural tachycardia syndrome. N Engl J Med. 2000;343:1008-14.

43. Stewart JM, Medow MS, Glover JL, Montgomery LD. Persistent splanchnic hyperemia during upright tilt in postural tachycardia syndrome. Am J Physiol Heart Circ Physiol. 2006;290:H665-73.

44.• Gibbons CH, Bonyhay I, Benson A, Wang N, Freeman R. Structural and functional small fiber abnormalities in the neuropathic postural tachycardia syndrome. PLoS One. 2013;8:e84716. This study used a combination of quantitative sensory testing, quantitative sweat testing, and peripheral skin biopsy to define a subgroup of patients with "neuropathic POTS." They found that this group differed significantly from the "non-neuropathic POTS" group not only in terms of catecholamine level but also in terms of scores for depression and anxiety. This is an initial study pointing the way to endophenotyping in POTS

45. Fouad FM, Tadena-Thome L, Bravo EL, Tarazi RC. Idiopathic hypovolemia. Ann Intern Med. 1986;104:298-303.

46. Raj SR, Biaggioni I, Yamhure PC, Black BK, Paranjape SY, Byrne DW, et al. Renin-aldosterone paradox and perturbed blood volume regulation underlying postural tachycardia syndrome. Circulation. 2005;111:1574-82.

47. Lin CJ, Chu YK, Chern CM. RBC volume deficiency in patients with excessive orthostatic decrease in cerebral blood flow velocity. J Chin Med Assoc. 2014;77:174-8.

48. Jackson EK. Renin and angiotensin. In: Hardman JG, Limbird LE, editors. Goodman \& Gilman's the pharmacological basis of therapeutics. New York: McGraw-Hill; 2001.

49. Stowasser M, Ahmed AH, Pimenta E, Taylor PJ, Gordon RD. Factors affecting the aldosterone/renin ratio. Horm Metab Res. 2012;44:170-6.

50. Mustafa HI, Garland EM, Biaggioni I, Black BK, Dupont WD, Robertson D, et al. Abnormalities of angiotensin regulation in postural tachycardia syndrome. Heart Rhythm. 2011;8:422-8.

51. Stewart JM, Glover JL, Medow MS. Increased plasma angiotensin II in postural tachycardia syndrome (POTS) is related to reduced blood flow and blood volume. Clin Sci (Lond). 2006;110:255-63.

52. Furlan R, Jacob G, Snell M, Robertson D, Porta A, Harris P, et al. Chronic orthostatic intolerance: a disorder with discordant cardiac and vascular sympathetic control. Circulation. 1998;98:2154-9.

53. Garland EM, Raj SR, Black BK, Harris PA, Robertson D. The hemodynamic and neurohumoral phenotype of postural tachycardia syndrome. Neurology. 2007;69:790-8.
54. Shannon JR, Flattem NL, Jordan J, Jacob G, Black BK, Biaggioni I, et al. Orthostatic intolerance and tachycardia associated with norepinephrine-transporter deficiency. N Engl J Med. 2000;342: 541-9.

55. Lambert E, Eikelis N, Esler M, Dawood T, Schlaich M, Bayles R, et al. Altered sympathetic nervous reactivity and norepinephrine transporter expression in patients with postural tachycardia syndrome. Circ Arrhythm Electrophysiol. 2008;1:103-9.

56. Shibao C, Arzubiaga C, Roberts LJ, Raj S, Black B, Harris P, et al. Hyperadrenergic postural tachycardia syndrome in mast cell activation disorders. Hypertension. 2005;45:385-90.

57.• Li H, Yu X, Liles C, Khan M, Vanderlinde-Wood M, Galloway A, et al. Autoimmune basis for postural tachycardia syndrome. J Am Heart Assoc. 2014;3:e00755. This study found the presence of partial agonist alpha-1 adrenergic antibodies and agonist betaadrenergic autoantibodies in a high percentage of POTS patients. While preliminary, these data suggest a mechanism to explain the relatively common onset of POTS after a viral-like illness.

58. Jacob G, Shannon JR, Black B, Biaggioni I, Mosqueda-Garcia R, Robertson RM, et al. Effects of volume loading and pressor agents in idiopathic orthostatic tachycardia. Circulation. 1997;96:575-80.

59. Smit AA, Wieling W, Fujimura J, Denq JC, Opfer-Gehrking TL, Akarriou M, et al. Use of lower abdominal compression to combat orthostatic hypotension in patients with autonomic dysfunction. Clin Auton Res. 2004;14:167-75.

60. Masuki S, Eisenach JH, Schrage WG, Dietz NM, Johnson CP, Wilkins BW, et al. Arterial baroreflex control of heart rate during exercise in postural tachycardia syndrome. J Appl Physiol (1985). 2007;103:1136-42.

61. Masuki S, Eisenach JH, Schrage WG, Johnson CP, Dietz NM, Wilkins BW, et al. Reduced stroke volume during exercise in postural tachycardia syndrome. J Appl Physiol (1985). 2007;103: 1128-35.

62. Fu Q, Vangundy TB, Shibata S, Auchus RJ, Williams GH, Levine BD. Exercise training versus propranolol in the treatment of the postural orthostatic tachycardia syndrome. Hypertension. 2011;58: $167-75$.

63. Shibata S, Fu Q, Bivens TB, Hastings JL, Wang W, Levine BD. Short-term exercise training improves the cardiovascular response to exercise in the postural orthostatic tachycardia syndrome. J Physiol. 2012;590:3495-505.

64. Raj SR, Black BK, Biaggioni I, Paranjape SY, Ramirez M, Dupont $\mathrm{WD}$, et al. Propranolol decreases tachycardia and improves symptoms in the postural tachycardia syndrome: less is more. Circulation. 2009; 120:725-34.

65. Raj SR, Black BK, Biaggioni I, Harris PA, Robertson D. Acetylcholinesterase inhibition improves tachycardia in postural tachycardia syndrome. Circulation. 2005;111:2734-40.

66. Kanjwal K, Karabin B, Sheikh M, Elmer L, Kanjwal Y, Saeed B, et al. Pyridostigmine in the treatment of postural orthostatic tachycardia: a single-center experience. Pacing Clin Electrophysiol. 2011;34:750-5.

67. Benarroch EE. Postural tachycardia syndrome: a heterogeneous and multifactorial disorder. Mayo Clin Proc. 2012;87:1214-25.

68. Hoeldtke RD, Bryner KD, Hoeldtke ME, Hobbs G. Treatment of postural tachycardia syndrome: a comparison of octreotide and midodrine. Clin Auton Res. 2006;16:390-5.

69. Kanjwal K, Saeed B, Karabin B, Kanjwal Y, Grubb BP. Use of octreotide in the treatment of refractory orthostatic intolerance. Am J Ther. 2012;19:7-10.

70. McDonald C, Frith J, Newton JL. Single centre experience of ivabradine in postural orthostatic tachycardia syndrome. Europace. 2011;13:427-30.

71. Nwazue VC, Raj SR. Confounders of vasovagal syncope: postural tachycardia syndrome. Cardiol Clin. 2013;31:101-9. 
72. Coffin ST, Black BK, Biaggioni I, Paranjape SY, Orozco C, Black PW, et al. Desmopressin acutely decreases tachycardia and improves symptoms in the postural tachycardia syndrome. Heart Rhythm. 2012;9:1484-90.

73.• Green EA, Raj V, Shibao CA, Biaggioni I, Black BK, Dupont WD, et al. Effects of norepinephrine reuptake inhibition on postural tachycardia syndrome. J Am Heart Assoc. 2013;2:e00395. This acute randomized, placebo-controlled crossover trial of atomoxetine (a norepinephrine transport inhibitor (NETi)) in POTS patients found that atomoxetine increased heart rate and worsened symptoms. NETi is a mechanism commonly found in many psychotropic medications.

74.• Mar PL, Raj V, Black BK, Biaggioni I, Shibao CA, Paranjape SY, et al. Acute hemodynamic effects of a selective serotonin reuptake inhibitor in postural tachycardia syndrome: a randomized, crossover trial. J Psychopharmacol. 2014;28:155-61. This acute randomized, placebo-controlled crossover trial of sertraline (a selective serotonin reuptake inhibitor (SSRI)) in POTS patients found that sertraline induced a modest increase in blood pressure, but no effect on heart rate or symptoms. 